\title{
Research of Project Portfolio Selection Model Based on Organizational Strategy
}

\author{
Yaping $\mathrm{WANG}^{1}$ \\ ${ }^{1}$ Shool of Management Xi'an mingde institute of technology,Xi'an, P. R. China, 710072
}

\begin{abstract}
Based on the theory of the existing research of the project portfolio management, the paper analyzes the key factors of the project portfolio selection, and evaluates them using the fuzzy comprehensive evaluation method. Finally, the paper builds a project portfolio choice integer programming model based on $0 / 1$ integer programming, which is based on the organizations strategies.
\end{abstract}

\section{Introduction}

With the rapid economic growth, enterprises are increasingly facing the problem of how to select several projects from multiple projects to form a project portfolio. How companies should make decisions to obtain the best benefits. How to carry out the project portfolio to achieve the company's strategic goals? At present, most of the research on this issue is aimed at single-project research. There is a difference between single-item selection and multi-item selections at the same time. When comparing and choosing between single projects, more considerations are profitability, technical feasibility, etc.; when comparing and choosing from project portfolios, more consideration is between projects within the project portfolio from the perspective of corporate strategy. Business decision-makers should pay attention to the interdependence between projects, and at the same time, they should pay attention to corporate strategy. ${ }^{1}$ When projects are interdependent, even a moderate number of project selections with a few optimization goals and constraints can become quite complicated.

Project portfolio management is not simply managing multiple projects. Each project portfolio needs to be evaluated according to its own business value and company strategy, and to achieve certain business goals or business benefits. Project portfolio management ensures the consistency between the project and the company's strategic goals through project evaluation and selection and portfolio optimization, so as to maximize the benefits of the company. As a bridge between corporate projects and strategies, project portfolio management goes beyond the boundaries of traditional project management, combining project implementation with corporate business strategies.

How to select several projects from multiple candidate projects to form a project portfolio based on the strategic orientation of the organization? Researchs on this issue are relatively lacking. The company's assessment and decision-making of the project portfolio directly affects the company's strategy. Therefore, the research on project selection in project portfolio management has very important theoretical value and practical significance.

\section{Research status}

Project Management Institute ${ }^{[1]}$ believed that project portfolio is a collection of projects or programs and their work that are effectively managed to meet the strategic goals of the organization.He'lio R. Costa ${ }^{[2]}$ studied the strategic management of software project portfolio from the perspective of avoiding project risks through the analysis of economic effects, and applies it to practice. In the case, the company's strategic goals are basically achieved. Sascha Meskendahl ${ }^{[3]}$ studied the relationship between project portfolio management and the realization of corporate strategic goals, and proposed a comprehensive conceptual model of strategy, project portfolio, etc. to guide the smooth implementation of the project. PMA Research Committee Chairman Roland Gareis $^{[4]}$ proposed that the project portfolio is a collection of all projects and plans held by a project-oriented organization at a specific point in time and the links between these projects and plans; Chinho Lin $^{[5]}$ proposed a complete framework model in the DSS system on the basis of the fuzzy theory, for the realization of strategic objectives of project portfolio management, and the feasibility of the model is verified according to actual examples.

Domestic research mainly focuses on the specific formulation of corporate strategy ${ }^{[6]}$. However, the research on optimization of project portfolio management that rises to strategic goals is very limited. Zhai Lei and Qi Anbang [7] are analyzing the relationship between corporate strategy and project portfolio design and management. On 
the basis of the EVA, the enterprise strategy-based project portfolio design and management process was obtained to realize the unification of corporate strategy and project design and implementation. Yang Xiaoping ${ }^{[8]}$ focused on analyzing the key influencing factors of project selection in project management, and established an evaluation index system for project selection in project management based on a combination of qualitative and quantitative analysis. Based on the existing theories of project portfolio management, this paper analyzes the key influencing factors of project portfolio selection, and evaluates the key influencing factors using fuzzy comprehensive evaluation method, and finally constructs project portfolio selection based on $0 / 1$ integer planning Integer programming model. To make the project portfolio management better serve the organization strategy and maximize corporate value.

\section{Analysis of key influencing factors of project selection in project portfolio management}

The selection of projects in project portfolio management is directly related to the success or failure of the enterprise. Therefore, when selecting candidate projects, the enterprise needs to follow strict procedures and guidelines, and consider appropriate influencing factors to evaluate the choice of a project.

A.Corporate strategy is the fundamental basis for an enterprise to carry out project portfolio management. Many companies at home and abroad have deeply realized the importance of corporate strategy, so they first consider selecting projects that have a large contribution to the realization of organizational strategy. The contribution of the project portfolio to the organization's strategic goals is mainly reflected in the impact of the project portfolio on the company's sustainable development capabilities, mainly in: 1)long-term benefits; 2)talent training; 3) organizational structure adjustment; 4)social benefits; 5)reputation and social visibility. That is as shown in Figure 1.

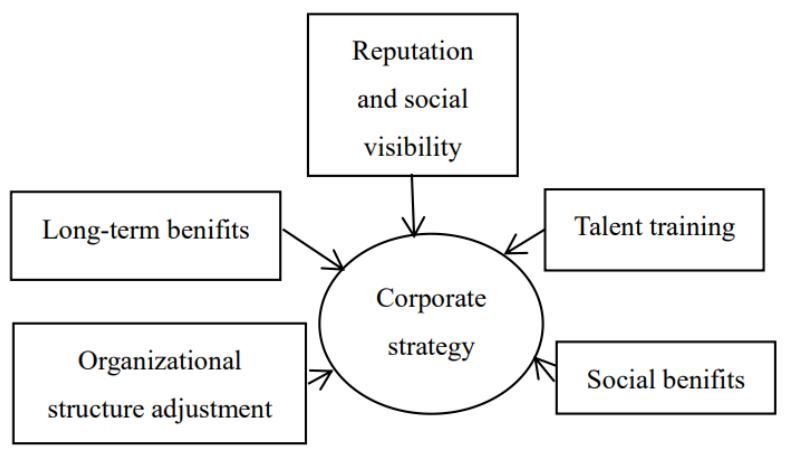

Figure 1: The project portfolio on the sustainable development

B.Need to consider the resources that the organization must be able to meet the project portfolio needs. Mainly manifested in: 1)human resources; 2)material resources; 3)information resources; 4)financial resources; 5)technical resources.

In addition, the economic benefits expected from the project portfolio need to be considered. The goal pursued by the enterprise is to maximize the value of the enterprise, so the ultimate goal of the enterprise choosing the project portfolio is also to maximize the value of the enterprise, so the expected economic benefits of the project portfolio are important factors that need to be considered. For example, economic returns can be used to measure the size of economic benefits, profit contribution (for example, five-year financial cumulative net present value minus R\&D expenses), payback period (the year when the accumulated cash flow is equal to R\&D expenses), or the time to market, etc. So that the indicators are measured.

C.The economic benefits expected from the project portfolio which need to be considered. The goal pursued by the enterprise is to maximize the value of the enterprise, so the ultimate goal of the enterprise choosing the project portfolio is also to maximize the value of the enterprise. Thus, the expected economic benefits of the project portfolio are important factors that need to be considered. For example, economic returns can be used to measure the size of economic benefits, profit contribution (for example, five-year financial cumulative net present value minus R\&D expenses), payback period (the year when the accumulated cash flow is equal to R\&D expenses), or the time to market, etc. So that the indicators are measured.

D. The risk of the project portfolio is also a factor that must be considered. Benefits and risks always go hand in hand. Only by recognizing the investment risks of the project and investing correctly can it bring benefits to the enterprise and realize the strategic goals of the organization. Therefore, the investment risks brought by the project portfolio should be considered when selecting the project portfolio, including: 1)external risks; 2)internal risks.

The risk of the project portfolio can be measured from the probability of commercial success and the probability of technical success. The probability of commercial success can be considered from the following aspects: 1) existing market demand; 2) market maturity (decline or rapid rise); 3) degree of competition (competitive technologies and competitors); 4) business development platform (new business or existing business model); 5) business assumptions (low probability or predictable); 6) legal/social/political influence. The same probability of technical success can be considered: 1) technology gap (from huge gap to step improvement); 2) technical complexity; 3) technical foundation (from completely unfamiliar to enterprise already has extensive practice); 4) The availability of personnel and facilities (from new construction, reconstruction to ready-made).

In addition, the Project Portfolio Management Office should also play the following roles in portfolio selection: 1)It should organize experts and representatives of various departments to formulate evaluation criteria for project portfolio optimization. Prioritization of projects is the key to project portfolio selection. Therefore, it is necessary to formulate selection evaluation criteria for project portfolios, and evaluate all projects according to the same standard. 2) It also should organize experts and representatives of various departments to evaluate and screen the project. Prioritize the project in accordance with the evaluation criteria. 3) We should effectively integrate and implement the selected projects to maximize the 
benefits of the enterprise.

\section{Comprehensive evaluation of the key influencing factors of project selection}

Thiry believes that although project portfolio management is similar to single project management, it should be noted that project portfolio management not only manages large projects, but also has a higher degree of complexity and uncertainty. The goals of project portfolios are dynamic and ambiguous. Therefore, the special attributes of the project portfolio determine that the key influencing factors of project selection often require a large number of qualitative evaluations. Now the fuzzy comprehensive evaluation method is used to evaluate the key influencing factors of project selection. Now take the resources required for the project portfolio as an example for analysis.

$$
\begin{aligned}
& \text { A. Establish a set of judgement factors } U \text {. } \\
& U=\left(u_{1}, u_{2}, \cdots, u_{i}, \cdots, u_{n}\right) \\
& i=1,2, \cdots, n \\
& \text { B.Create a judgment set } V \\
& V=\left(v_{1}, v_{2}, \cdots, v_{j}, \cdots, v_{m}\right) \\
& j=1,2, \cdots, m
\end{aligned}
$$

C.The degree of membership is used to describe the degree of membership of the highest-level sub-factors relative to the evaluation set, and a single-factor fuzzy evaluation matrix is obtained, which represents the degree of membership of the evaluation factor to the evaluation set. It can be obtained through expert voting and other methods.

$$
\begin{aligned}
R & =\left[\begin{array}{cccccc}
r_{11} & r_{12} & \cdots & r_{1 j} & \cdots & r_{1 m} \\
r_{21} & r_{22} & \cdots & r_{2 j} & \cdots & r_{2 m} \\
\cdots & \cdots & \cdots & \cdots & \cdots & \cdots \\
r_{i 1} & r_{i 2} & \cdots & r_{i j} & \cdots & r_{i m} \\
\cdots & \cdots & \cdots & \cdots & \cdots & \cdots \\
r_{n 1} & r_{n 2} & \cdots & r_{n j} & \cdots & r_{n m}
\end{array}\right]_{n \times m} \\
0 \leq r_{i j} \leq 1, \quad \sum_{j=1}^{m} r_{i j}=1 &
\end{aligned}
$$

\section{D.Single-level fuzzy evaluation}

Firstly, AHP method or expert opinion method is used to establish the weight set of the highest level sub-factor set $\mathrm{W}$.

$$
\begin{aligned}
& W=\left(w_{1}, w_{2}, \cdots, w_{i}, \cdots, w_{n}\right) \\
& i=1,2, \cdots, n
\end{aligned}
$$

Then use the formula to calculate the single-level fuzzy evaluation result $\mathrm{B}$

$$
\begin{aligned}
& B=W \bullet R=\left(b_{1}, b_{2}, \cdots, b_{j}, \cdots, b_{m}\right) \\
& b_{j}=\sum_{i=1}^{n}\left(w_{i} \cdot r_{i j}\right)
\end{aligned}
$$

$$
j=1,2, \cdots, m
$$

E.Multi-level comprehensive fuzzy evaluation

Firstly, the factor set $\mathrm{U}$ is divided into various levels of factor sets, and then starting from the highest level factor set.The single-level fuzzy evaluation method is used to evaluate layer by layer, and finally a comprehensive evaluation $B$ is obtained through the evaluation of the first layer factor set. If the evaluation set is expressed in quantification, which is:

$$
\begin{aligned}
& V=\left(v_{1}, v_{2}, \cdots, v_{j}, \cdots, v_{m}\right)^{T} \\
& j=1,2, \cdots, m
\end{aligned}
$$

Then the total score of multi-layer fuzzy evaluation can be obtained as

$$
P=\left(b_{1}, b_{2}, \cdots, b_{n}\right)\left(v_{1}, v_{2}, \cdots, v_{m}\right)^{T}
$$

The value $\mathrm{P}$ can be calculated.

By analogy, we can calculate the $P$ value of each key influencing factor.

\section{Build a portfolio selection model}

Based on the comprehensive evaluation values of the key influencing factors of the four project portfolios, the integer programming model of project portfolio selection is constructed under the constraints of the organizational strategic contribution, corporate resources, economic benefits generated by the project portfolio, and project portfolio risks.

$X_{i}$ represents the $0 / 1$ decision variable of whether the $i$ project is adopted. Because the economic benefits generated by the project are directly proportional to the contribution to the realization of the organizational strategy. $U_{i}$ is used to represent the economic benefits generated by the $\mathrm{i}$ project and the comprehensive evaluation value of the contribution to the realization of the organizational strategy. $R_{i}$ represents the risk of item $i$. $\mathrm{M}$ is the maximum risk that the project portfolio can bear, that is, it represents the size of the risk tolerance of the project portfolio. $i=(1,2, \cdots, p), p$ represents the number of items in the combination.

Objective function: The goal of the model is to produce the greatest economic benefits and enable the organization's strategy to be realized, namely

$$
\operatorname{MAX} \sum_{i=1}^{p} X_{i} U_{i}
$$

Resource constraints: In an organization, the $\mathrm{j}$ resource Aj used for the project portfolio is limited. At this time, the constraint can be expressed as:

$$
\sum_{i=1}^{\mathrm{p}} X_{i} A_{i j} \leq A_{j}
$$

Aj represents the number of the $\mathrm{j}$ resource required by project $\mathrm{i}(\mathrm{j}=1,2, \cdots, \mathrm{K})$; $\mathrm{k}$ represents the total number of resources.

Risk constraint: In order to control the risk level of the project portfolio within a certain limit, the constraint condition can be expressed as: 


$$
\sum_{i=1}^{p} X_{i} R_{i} \leq M
$$

Project Group Management [J], Project Management Technology, 2020.9:(3)

\section{Conclusion}

Based on the existing theories of project portfolio management, this paper analyzes the key influencing factors of project portfolio selection, and uses fuzzy comprehensive evaluation method to evaluate the key influencing factors, and finally builds the project portfolio selection based on $0 / 1$ integer programming model. It has achieved the goal of making project portfolio management better serve the organization's strategy and maximized corporate value.

Due to the limited space of this article and the limited level of my research, the research on the strategicallyoriented project portfolio management model has just begun, and many issues still need to be studied carefully. This model still deserves to be improved and studied in depth.

\section{Acknowledgment}

This work is supported by the 2019 Research Fund Project of Mingde College, Northwestern Polytechnical University (2019XY04W10) and Shaanxi Provincial Department of Education 2020 General Special Scientific Research Project(20JK0396)

\section{References}

1. The Project Management Institute, Inc. A Guide to the Project Management Body of Knowledge - Third Edition [S]. Newtown Square, Pennsylvania USA: Project Management Institute, inc. 2004, 11:245.

2. He'lio R. Costa a,b, Marcio de O. Barros b,c, Guilherme H. Travassos, Evaluating software project portfolio risks $[\mathrm{J}]$. The Journal of Systems and Software, 2007 (80):16-31.

3. Sascha Meskendahl. The influence of business strategy on project portfolio management and its success - A conceptual framework [J]. International Journal of Project Management , 2010 (28): 807-817.

4. The Project Management Institute, Inc. Project Portfolio Management Basics, Knowledge \& Wisdom [J]. 2003, 3.

5. Chinho Lina, b, Ping-Jung HsiehcA fuzzy decision support system for strategic portfolio management[J]. Decision Support Systems , 2004 (38) :383-398.

6. Ruichun Duan, Innovative Enterprise: Intellectual Property and Brand Strategy [J].China Soft Science, 2015 (12) : : $1-5$.

7. Lei Zhai,Anbang Qi.Design and Management of Enterprise Project Portfolio Based on Strategy [J]. Project Management Technology, 2018, 2: $17-21$.

8. Xiaoping Yang, Jiangbo He.Research on the Evaluation Index System of Project Selection in 